\title{
LETTERS
}

\section{Need caring, compassion or comfort? Sorry, I'm a doctor}

Ms. Manzoor and Dr. Redelmeier's ${ }^{1}$ CMAJ Humanities article on sexism in medical care introduces 7 strategies a female physician might employ when mistaken as a nurse by a patient in hospital. Although well intentioned, we believe the article perpetuates harmful gendered discourses about nursing and nursing work (e.g., hygiene, comfort, empathy, nutrition, mobility and information) that are important to critique.

The authors depict nursing as a series of "mundane" interventions such as scratching backs, fetching basins and delivering blankets. These delimited accomplishments obscure the diversity and importance of nursing in the contemporary health care environment. Readers are made to understand the "basic" work of nursing is not equivalent to the important "cognitive" work of medicine. Nurses, who remain primarily women, have long faced difficulties in their work environment as a result of centralized male positions of medical power. Difficulties include gender biases and role stereotypes that retain the notion that nursing comprises unskilled feminine tasks that are beneath the status or concern of the physician.

Patients and families expect clinicians, regardless of their gender or profession, to intervene in the bodily and social dilemmas that accompany serious illness and dying. The complex needs of the contemporary hospital patient require the collaboration of multiple professions. Sexist discourses of mundane nursing care impede this imperative. Social denigration of nursing can lead trainees, clinicians and administrators to believe physical or relational care is not a priority or an efficient use of their time. Misperceptions of nursing work as unskilled or undemanding may also contribute to the downloading of new administrative duties to the nursing profession. The resultant time compression experienced by nurses can impede the delivery of essential nursing care and pose dangerous consequences for patients.

In our analysis of the article, patient needs for comfort, empathy and information are subverted to the need for female physicians to maintain status. As the building blocks for hospital care, nursing interventions warrant the collective attention of physicians. Current research has shown that omissions of physical and relational nursing result in poor outcomes in patients including health care-acquired infections, pressure ulcers, falls, prolongation of treatment and hospital readmission. ${ }^{2-4}$ Investigation into failures of the health system include normalized disregard for patient needs (e.g., The Francis Inquiry $)^{5-7}$ and the social and political conditions that impede nursing intervention (e.g., missed nursing care). Finally, physicians also need to show compassion in their work rather than relegating these important patient-centred aspects of care to nurses.

As a reformulation of proposed strategies to combat sexism in health care, we suggest female physicians consider solidarity with nursing. This might include attention to gendered assumptions in language when describing nursing work. Professional admiration might go beyond nursing ability to silence beeping intravenous pumps. Blunt efficiency might include critical questions about the impact of nursing layoffs or the downloading of added administrative tasks to nursing. Bedside manners might include medical introductions to the patient and nurse and collegial humour when one forgets to do so.
Finally, we argue that a superior medical authority is not required to intervene when someone is treating a female, male or transgender clinician in an inappropriate manner.

\section{Craig Dale RN PhD}

Assistant professor, Lawrence S.

Bloomberg Faculty of Nursing, University of Toronto, Toronto, Ont.

\section{Fiona Webster PhD}

Associate professor, Arthur Labatt Family School of Nursing, Western University, London, Ont.

- Cite as: CMAJ 2020 June 22;192:E687. doi: $10.1503 / \mathrm{cmaj} .75183$

\section{References}

1. Manzoor F, Redelmeier DA. Sexism in medical care: "Nurse, can you get me another blanket?" CMAJ 2020;192:E119-20.

2. Ausserhofer D, Zander B, Busse R, et al. Prevalence, patterns and predictors of nursing care left undone in European hospitals: results from the multicountry cross-sectional RN4CAST study. BMJ Qual Saf 2014;23:126-35.

3. Krumholz HM. Post-hospital syndrome - an acquired, transient condition of generalized risk. NEJM 2013;368:100-2.

4. Ball JE, Bruyneel L, Aiken LH, et al. Post-operative mortality, missed care and nurse staffing in nine countries: a cross-sectional study. Int J Nurs Stud 2018;78:10-5.

5. The Mid Staffordshire NHS Foundation Trust Inquiry. Independent inquiry into care provided by Mid Staffordshire NHS Foundation Trust January 2005 - March 2009. London: Department of Health, 2010. Available: https://assets.publishing .service.gov.uk/government/uploads/system/ uploads/attachment_data/file/279109/0375_i. pdf (accessed 2020 June 4).

6. Gordon S. Nursing against the odds: how health care cost cutting, media stereotypes, and medical hubris undermine nurses and patient care. Ithaca (NY): ILR Press, an imprint of Cornell University Press; 2005

7. Park SH, Hanchett M, Ma C. Practice environment characteristics associated with missed nursing care. J Nurs Scholarsh 2018;50:722-30.

Competing interests: None declared. 